www.jmscr.igmpublication.org Impact Factor 5.244

Index Copernicus Value: 5.88 ISSN (e)-2347-176x ISSN (p) 2455-0450 crossref DOI:_http://dx.doi.org/10.18535/jmscr/v4i6.59

\title{
Does Hepatitis C Affect Hematological Parameters, Co Morbidity And Functional Status In Hemodialysis Pateints?
}

\section{Authors \\ Ahmed Ramadan, Hesham Abouellail, Sahar Shawky, Sameh Abdelraouf}

Department of Medicine, Ain Shams University

\begin{abstract}
Objectives: Hepatitis $C$ is a serious public health problem throughout the world; chronic renal patients are highly exposed to this infection. As a chronic disease it will affect all body systems, the present study investigated the effect of $\mathrm{HCV}$ infection on hematologic parameters, comorbidities \& functional statusin the hemodialysis population in our outpatient hemodialysis unit and how much extend of Epo \& Iron requirement in these patients over 6 months of study.

Patients and Methods: the hematological parameters were assessed in 63 hemodialysis patients after their consents on regular thrice weekly hemodialysis schedules for at least 6 months, divided into two groups according to Hepatitis $C$ virus screening by antibodies and HCV - RNA PCR(23 patients with HCV +ve,12 males \& 11 females, and 40 patients HCV-ve,24 females\& 16 males as a control group of age-matched, racematched, and gender-matched). Exclusion criteria included polycystic kidney disease, cryoglobulinemia, hepatitis B, active malignancy, hematopoietic disorders (including multiple myeloma), chronic infections (including osteomyelitis), those with any massive blood loss or history of blood transfusion, liver cell failure, active treatment with interferon and or ribavirin and the presence of mass or multiple cysts on renal ultrasound. Patients had to be stable on hemodialysis for at least 6 months with a urea reduction ratio (URR)>65\% and demonstrate compliance with fewer than 3 missed dialysis sessions per month. All the patients were subjected to: Detailed medical history, clinical examination and monthly laboratory tests to evaluate liver function tests and hematological parameters (serum Albumin, Alanine Aminotransferase (ALT), iron, Transferrin saturation $\%(T R F S \%)$ and Hemoglobin(HB).Their requirements of erythropoietin (EPO-beta, Mircera) and intravenous (IV) iron (Ferric Carboxymaltose, FerinJect) were assessed during these 6 months of clinical stability. the comorbidities and the functional status were assessed by using Index of Coexisting Diseases (ICED)\& Karnofsky Index (KI)

Results: Both groups were able to achieve adequate blood hemoglobin (HB) above $11 \mathrm{gm} / \mathrm{dl}$, serum iron and transferring saturation (TRFS \%) between 20-50 \% according to KDOGJ guidelines, there was significant higher serum level regarding $H B \&$, iron at zero, 3 and 6 months $(P<0.05)$ in $H C V+v e$ group than negative group, and also HCV +ve patients showed statistically highly significant difference in TRFS\% in comparison with $H C V$-ve cases $(P<0.001)$.. Regarding liver parameters HCV +ve cases showed higher levels of ALT only at 6 months samples $(P<0.05)$ \& higher levels of serum albumin in all studied but achieved the statistically high significant level only at 3 months $(P<0.05))$.In $H C V+$ ve group, there was no statistically significant difference in blood $H B$ and serum iron $(P>0.05)$ when compared with the started study levels by 3 and 6 months levels respectively $(P>0.05)$ but TRFS\% showed statistically high significant difference $(P<0.001)$ when compared the started by 3 months and 6 months levels respectively, serum ALT and serum Albumin show stable levels and there were no significant changes during the period of the study $(P>0.05)$.
\end{abstract}


The exogenous EPO-beta requirement of patients with $\mathrm{HCV}+\mathrm{ve}$ was overall significantly lower even when adjusted for body weight ( the total dose of Epo- beta, Mircera was lower in HCV +ve patients of $718.3 \pm 58.3$ ug than HCV -ve of $1937 \pm 400 \mathrm{ug} / 6$ months ,p $<0.001$ ). and also the total dose of IV Iron, Ferin Ject at 6 months was lower in positive group than the control, $1.117 \pm 0.23$ and $2.5 \pm 0.64$ gm respectively $p<0.001$. No statistics difference between both groups regarding the comorbidities using the Index of Coexisting Diseases (ICED) \& functional status by KI index, $P>0.05$

Conclusion: So we concluded that Hepatitis $C$ positive patients tend to have higher baseline hemoglobin, serumiron, serum TRFS \% and decreased need for EPO \& IV Iron therapy on dialysis, but we study only stable compensate $\mathrm{HCV}+v e$ without viral activity. The possible explanation for these findings may be the release of hepatic EPO because of chronic hepatic inflammation secondary to HCV; further studies needed in decompensated HCV for more data.

Keywords: hemodialysis, hepatitis $C$, hematological parameters, IV Epo, IV Iron co morbidities (ICED), Functional Index ( KI ).

\section{Introduction}

Approximately 170 million people are infected with hepatitis $\mathrm{C}$ virus (HCV) worldwide. Hepatitis $\mathrm{C}$ is a serious public health problem throughout the world this infection has been the cause of chronic hepatitis, cirrhosis, and hepatocellular carcinoma. Blood-transfused individuals and patients who have undergone invasive medical procedures such as hemodialysis have been considered to be at high risk for hepatitis C infection $^{(1)}$.

Chronic renal patients are highly exposed to this infection. This could be due to a failure to identify carriers of this disease or because of a lack of truly effective bio safety measures implemented in the dialysis units. Molecular biology techniques have allowed for the understanding of this virus in detail, including its replication mechanisms.

Epidemiological studies have been made throughout the world, with the goal of determining the dissemination dynamics of this agent, in addition to examining the predominance of the different genotypes, and the possible mutants that are involved. Many questions must still be answered concerning infection by Hepatitis $\mathrm{C}$ virus (HCV); this is especially important for immune suppressed patients. The prevalence of $\mathrm{HCV}$ antibodies has been reported to range from $3 \%$ in hemodialysis patients in the USA to more than $70 \%$ in Eastern Europe ${ }^{(2)}$.

Anti HCV testing has now become routine in most dialysis units across the world as since its first diagnosis in 1989 it has been a significant viral infection among hemodialysis patients ${ }^{(3)}$. Patients with end-stage renal disease (ESRD) on dialysis have depressed alanine aminotransferase (ALT) levels, making the antibody testing the only reliable modality to diagnose this infection ${ }^{(4)}$

Hepatitis C is a serious public health problem throughout the world; chronic renal patients are highly exposed to this infection. This could be due to a failure to identify carriers of this disease or because of a lack of truly effective bio safety measures implemented in the dialysis units. Molecular biology techniques have allowed for the understanding of this virus in detail, including its replication mechanisms. With technological advances in studies concerning the Hepatitis C virus (HCV), the elaboration and the implementation of diagnostic tests, such as triage in blood banks that began in 1990, has allowed professionals to understand the dimension of the Hepatitis C problem. It is known today that approximately 200 million people worldwide are infected by $\mathrm{HCV}^{(3)}$.

The main transmission route of $\mathrm{HCV}$ is parenteral ${ }^{(3-5)}$; however, approximately $10 \%$ of the cases are sporadic, without well-defined transmission routes ${ }^{(7,8)}$. The populations most affected by HCV are patients that undergo multiple blood transfusions, individuals who are intravenous and inhalant drug users, hemophiliacs, and hemodialysis patients ${ }^{(3,8)}$. The high prevalence of HCV infections in patients that undergo hemodialysis has been described worldwide ${ }^{(9-13)}$. 
The introduction of recombinant erythropoietin (EPO) for management of anemia in the dialysis population minimized the need for frequent blood transfusions, which has also helped in reducing the risk of exposure to $\mathrm{HCV}$. However, there continues to be a significant risk of transmission based on exposure to blood products, needle sticks, and through dialysis personnel ${ }^{(4)}$.

Sahin et al. have previously studied hemodialysis patients with $\mathrm{HCV}$ and suggested a lower EPO and iron requirement in these patients ${ }^{\left({ }^{9}\right)}$. Also Anan et al in 2008 had reported the same results in their in USA. ${ }^{(10)}$.

We have also observed a few patients in our dialysis units with $\mathrm{HCV}$ who had minimal requirement for EPO. This study was undertaken to assess the effect of HCV infection on anemia in the hemodialysis population in our outpatient unit and to study how much extent of Epo \& Iron requirement in these patients.

\section{Patients and Methods}

This study was conducted in the hemodialysis unitfrom March 2012 to October 2012. We studied 63 hemodialysis patients on regular thrice weekly hemodialysis schedules for at least 6 months, divided into two groups according to their hepatitis C markers: 23 patients (11females\&12 males) with $\mathrm{HCV}+\mathrm{ve}$ (patients were labeled as HCV-positive if they had Positive anti-HCV antibodies on 2 separate occasions \&On 1 occasion along with a confirmatory HCV polymerase Chain reaction testing or evidence of cirrhosis on liver imaging and/or biopsy ). and 40 patients (24 females\&16 males) with HCV -ve as control group.

Exclusion criteria included decompensated cardiac or pulmonary diseases, decompensated liver cirrhosis, polycystic kidney disease, cryoglobulinemia, hepatitis B, active malignancy, hematopoietic disorders (including multiple myeloma), chronic infections (including osteomyelitis), active gastrointestinal bleeding, active treatment with interferon and or ribavirin and the presence of mass or multiple cysts on renal ultrasound.

Patients had to be stable on hemodialysis for at least 6 months with a urea reduction ratio (URR) $>65 \%$ and demonstrate compliance with fewer than 3 missed dialysis sessions per month.

Both groups was matched regarding age ,sex, body mass index(BMI)and urea reduction ratio(URR) which was used as a marker for dialysis adequacy in hemodialysis patients all were $>65-70 \%$. This period was selected for each dialysis patient where they had no hospitallizations, major surgeries, episodes of GI bleeding, access clotting or bacteremia, or any other infections in a 4-week period before the blood draws.

The EPO doses (Mircera, Methoxy Polyethylene Glycol- Epoetin Beta) were reported as average monthly doses with the assumption that all patients in the study and control groups received all of their dialysis sessions each month. The body weight used was the reported dry weight on dialysis at the beginning of the 6-month period of lab draws. Intravenous-iron dose (Ferinject, Ferric Carboxymaltose, $500 \mathrm{mg} / 10 \mathrm{ml}$ vial) was also reported as the average monthly dose. Average dose for EPO and IV-iron were reported as mean \pm standard deviation. in our studied groups high titrated parenteral iron IV supplementation (Ferinject ,Ferric Carboxymaltose ,500 mg/ $10 \mathrm{ml}$ vial ) and S.C. or I.V. Erythropoietin (Mircera, Methoxy Polyethylene Glycol- Epoetin Beta) were considered to achieve an adequate blood HB (between $11-12 \mathrm{gm} / \mathrm{dl} \&$ not more than $12 \mathrm{gm}$ /dl ), serum iron and TRF\% ( from $20-40 \%$ ) in accordance with kidney disease outcomes quality innovative KDOGI guidelines5 milliliters of whole blood was collected in two test tubes the first EDTA tube for Hemoglobin assay and another plain tube for Alt, Albumin, ,iron profile centrifuged at $3000 \mathrm{rpm}$ for $10 \mathrm{~min}$. Serum and the red blood cells were separated. The collected serum was used to assess serum Albumin, Alanine Aminotransferase, iron and Transferrin saturation. All the biochemical tests were estimated by using 
a Beckman CoulterDXC 800autoanalyserKits and quality-controlled serum (synchron control level 1,2, and 3) were supplied by Beckman coulter, inc.USA.

The comorbidities were cataloged using the Index of Coexisting Diseases (ICED), a coding system that classifies the presence and severity of 19 different diseases and11 physical impairments ${ }^{(11)}$. Disease severity was scored on a scale from 0 to 3 , with 0 indicating the absence of disease, and increasing values indicating increasing severity of the disease. The highest scores of Index of Disease Severity (IDS) and Index of Physical Impairment (IPI) were combined to create the ICED score, from 0 to 3Functional status was assessed by means of the Karnofsky Index (KI)(12). The KI is an overall indicator of the patient's level of physical functioning and is used frequently in clinical research. KI scores range from 10(lowest level) to 100 (highest level).

\section{ICED and Karnofsky Index scoring systemProportionin cohort ${ }^{(11 \& 12)}$. \\ ICED}

ONo comorbidity

1. Asymptomatic to mildly symptomatic

2. Moderate symptoms, require medications for control of disease

3. 3 Severe symptoms, inadequate control of Disease despite maximal medical therapy

\section{Karnofsky Index}

100 Normal

90Normal activity; minor symptoms/signs of disease

80 Normal activity with effort

70 Cares for self

60 Self-care with minimal help

50 Self-care with considerable help

40 Disabled; needs special care

30 Severely disabled

20 Very sick; hospitalization needed

10 Moribund -

\section{Statistical Analysis:}

SPSS package version 11 for Windows was used for the statistical analysis of data. Student t-test was used to compare the mean levels between groups.

\section{Results}

Twenty - three patients had a confirmed diagnosis of $\mathrm{HCV}$ without complication on regular hemodialysis > 6 month ( 12 males \& 11 females ) were included for analysis based on the exclusion criteria outline above the control group of HCV ve was forty patients has similar age $\&$ gender as shown in table (1).

The underlying causes of the end stage renal failure in both groups were diabetic nephropathy both type 1 \& 2 in (45\%), chronic glomerulonephritis and hypertension (30\%) ,chronic interstitial nephritis from analgesics and herbals in (4\%), lupus nephritis \& vacuities in (16 $\%)$, obstructive uropathy in $(2 \%)$ and the remaining ( $3 \%$ ) had unknown etiology.

Both groups was matched regarding age, sex, body mass index(BMI)and urea reduction ratio (URR) which was used as a marker for dialysis adequacy in hemodialysis patients all were $>65$ $70 \%$.

Both groups were able to achieve adequate blood hemoglobin (HB), serum iron and transferrin saturation (TRFS\%) according to KDOGI guidelines, there was high serum level of both $\mathrm{Hb}$ \& iron at zero, 3 and 6 months $(\mathrm{P}<0.05)$ in $\mathrm{HCV}$ +ve group than HCV -ve group as shown in table (2) .

HCV +ve patients showed statistically highly significant difference in $\mathrm{TRF} \%$ in comparison with $\mathrm{HCV}-\mathrm{ve}$ cases $(\mathrm{P}<0.001)$, (figure 1). Regarding liver parameters $\mathrm{HCV}$ +ve cases showed higher levels of ALT only at 6 months samples $(\mathrm{P}<0.05)$ \& higher levels of serum albumin in all studied but achieved the statistically high significant level only at 3 months $(\mathrm{P}<0.05)$ as shown in table (2).

In $\mathrm{HCV}+\mathrm{ve}$ group, there was no statistically significant difference by paired $-t$ test in blood $\mathrm{HB}$ and serum iron $(\mathrm{P}>0.05)$ when compared with the study levels by 3 and 6 months levels respectively $(\mathrm{P}>0.05)$, but $\mathrm{TRFS} \%$ showed 
statistically high significant difference $(\mathrm{P}<0.001)$ when compared the started by 3 months and 6 months levels respectively as shown in table(3). Serum ALT and serum Albumin show stable levels and there were no significant changes during the period of the study $(\mathrm{P}>0.05)$.

Regarding the Epo. \& IV Iron requirements, there was highly significant $(\mathrm{P}<0.001)$ a lower IV Iron requirements in $\mathrm{HCV}+\mathrm{ve}$ group at $0,3,6$ month and the total doses ( $0.48 \pm 0.10,0.35$ $\pm 0.24,0.35 \pm 0.24 \& 1.17 \pm 0.24$ ) in comparison to $\mathrm{HCV}$ - ve group ( $1,0.8 \pm 0.46,0.734 \pm 0.45$ \& $2.5 \pm 0.64$ ), ( figure 3 ). Also there was a highly significant $(\mathrm{P}<0.001)$ Erythropoietin beta requirement doses in $\mathrm{HCV}$ - ve group at all months as shown in table (4) and figure ( 2 ).the cumulative total dose at 6 months of Epo was $718.3 \pm 58.3$ and $1937 \pm 400$ ug respectively $(\mathrm{P}<$ $0.001)$. There was negative correlation between the dose of IV Iron \& Epo in HCV -ve group ( $\mathrm{r}$ test, $-0.38, \mathrm{P}<0.01$ ), but did not find in positive group (r-test, 0.24, $\mathrm{P}>0.5$ ) .
In this study as shown in table (5) ICED score in $\mathrm{HCV}$-ve \& HCV +ve there was no statistically significant difference between both groups $(\mathrm{P}>0.05)$ in score asymptomatic, 2 and $3(\mathrm{P}>0.05)$.

Also there was no statistical correlation between the ICED score and blood HB, TRFS\%, serum iron and ALT in HCV +ve patients $(\mathrm{P}>0.05)$ at 0 , 3and 6 months.

Functional status was assessed by means of the Karnofsky Index (KI); the $\mathrm{KI}$ is an overall indicator of the patient's level of physical functioning. Range from 10 (lowest level) to 100 (higher level) (R).

Table (6) showed KI in both groups and the distribution in males and females there was no statistically significant difference between both groups $(\mathrm{P}>0.05)$.

In $\mathrm{HCV}+$ ve patients there was no statistically significant correlation between $\mathrm{KI}$ and blood $\mathrm{HB}$, serum iron, TRFS\%, ALT and serum Albumin at 0,3 and 6 months of studied period $(\mathrm{P}>0.05)$.

Table (1). The demographic characteristics of the two studied groups

\begin{tabular}{|l|l|l|l|}
\hline Variants & HCV+ve $\{23$ patients $\}$ & HCV-ve $\{40$ patients $\}$ & P value \\
\hline Age $\{$ year $\}$ & $59.1+\_11.85$ & $58.9+\_15.4$ & $>0.05$ \\
\hline Sex: & & & $>0.05$ \\
Females; & $11\{47.8 \%\}$ & $24\{60 \%\}$ & \\
Males ; & $12\{52.2 \%\}$ & $16\{40 \%\}$ & \\
\hline BMI & $20.9+\_2.4$ & $21.6+\_2.4$ & $>0.05$ \\
\hline URR $\{\%\}$ & $70 \pm 40.17$ & $69.4 \pm 3.7$ & $>0.05$ \\
\hline
\end{tabular}

P: statistical significant $<0.05$.

URR\%; Urea Reduction Ratio

Table (2): showed the hematological and liver function parameters in HCV +ve and -ve patients at the start of our study (baseline), at 3 and 6 month.

\begin{tabular}{|l|l|l|l|l|l|l|}
\hline variable & At 0 & $\begin{array}{l}\text { At } \\
\text { months }\end{array}$ & P- value & At 0 & At 6 months & P- value \\
\hline HB & $119 \pm 15.8$ & $118 \pm 17.6$ & $>0.05$ & $119 \pm 15.8$ & $119.3 \pm 26$ & $>0.05$ \\
\hline Iron & $15.2 \pm 6.2$ & $14.3 \pm 5.9$ & $>0.05$ & $15.2 \pm 6.2$ & $15.6 \pm 11.1 \pm 5.4$ & $>0.05$ \\
\hline TRFS \% & $\begin{array}{l}36.4 \pm \\
12.6\end{array}$ & $\begin{array}{l}39.7 \pm \\
12.9\end{array}$ & $<0.001^{* *}$ & $\begin{array}{l}36.4 \pm \\
12.6\end{array}$ & $43.1 \pm 11.9$ & $<0.001^{* *}$ \\
& $19.9 \pm 8.8$ & $\begin{array}{l}21.1 \pm \\
\text { ALT }\end{array}$ & $>0.05$ & $19.6 \pm 8.8$ & $21.3 \pm 9.6$ & $>0.05$ \\
& & & & & \\
\hline Alb. & $33.2 \pm 7.5$ & $31.3 \pm 3.8$ & $>0.05$ & $33.2 \pm 7.5$ & $31.2 \pm 5.6$ & $>0.05$ \\
\hline
\end{tabular}

$P$ : statistical significant $<0.05 *$. and a highly significant $<0.001 * *$

HB .serum hemoglobin, TRFS\%, Transferrin saturation \%, ALT, Alanine tansaminase\&ALB. Serum albumin. 
Table (3) showed the hematological and liver parameters in HCV +ve cases

\begin{tabular}{|c|c|c|c|c|c|c|c|c|c|}
\hline \multirow[t]{2}{*}{ variable } & \multicolumn{3}{|l|}{ At 0 time } & \multicolumn{3}{|c|}{ At 3 months } & \multicolumn{3}{|c|}{ At 6 months } \\
\hline & $\mathrm{HCV}+\mathrm{ve}$ & $\begin{array}{l}\mathrm{HCV}- \\
\text { ve }\end{array}$ & $\begin{array}{l}\mathrm{P}- \\
\text { value }\end{array}$ & $\begin{array}{l}\mathrm{HCV} \\
+\mathrm{ve}\end{array}$ & $\begin{array}{l}\mathrm{HCV} \\
-\mathrm{ve}\end{array}$ & $\begin{array}{l}\text { P- } \\
\text { value }\end{array}$ & $\begin{array}{l}\mathrm{HCV} \\
+\mathrm{ve}\end{array}$ & $\begin{array}{l}\mathrm{HCV}- \\
\text { ve }\end{array}$ & P-value \\
\hline $\mathrm{HB}(\mathrm{g} / \mathrm{L})$ & $119 \pm 15.8$ & $\begin{array}{l}11.5 \pm 12 \\
.6\end{array}$ & $\begin{array}{l}<0.05 \\
*\end{array}$ & $\begin{array}{l}118 \pm \\
17.6\end{array}$ & $\begin{array}{r}110.2 \\
\pm 11.2\end{array}$ & $\begin{array}{l}<0.05 \\
*\end{array}$ & $\begin{array}{l}119.3 \pm 2 \\
6\end{array}$ & $\begin{array}{l}107.2 \pm 1 \\
1.7\end{array}$ & $<0.05^{*}$ \\
\hline Iron(umol/L) & $15.2 \pm 6.2$ & $11.9 \pm$ & $\begin{array}{l}<0.05 \\
*\end{array}$ & $\begin{array}{l}14.3 \pm \\
5.9\end{array}$ & $\begin{array}{l}10.2 \pm \\
5.4\end{array}$ & $\begin{array}{l}<0.05 \\
* \\
\end{array}$ & $\begin{array}{l}15.6 \pm 6 . \\
7\end{array}$ & $\begin{array}{l}11.1 \pm 5 . \\
4\end{array}$ & $<0.05^{*}$ \\
\hline TRFS. $\%$ & $\begin{array}{l}36.4 \pm \\
12.6 \\
\end{array}$ & $\begin{array}{l}19.9 \\
\pm 17.5\end{array}$ & $\begin{array}{l}<0.00 \\
1 * *\end{array}$ & $\begin{array}{l}39.7 \\
\pm 12.9 \\
\end{array}$ & $\begin{array}{l}19.4 \\
\pm 17.9 \\
\end{array}$ & $\begin{array}{l}<0.00 \\
1 * *\end{array}$ & $\begin{array}{l}43.1 \\
\pm 11.9\end{array}$ & $\begin{array}{l}20.3 \\
\pm 18.2 \\
\end{array}$ & $\begin{array}{l}<0.001 * \\
*\end{array}$ \\
\hline ALT(IU/L) & $19.9 \pm 8.9$ & $\begin{array}{l}19.6 \\
\pm 11.9 \\
\end{array}$ & $>0.05$ & $\begin{array}{l}21.1 \pm \\
12.6 \\
\end{array}$ & $\begin{array}{r}16.8 \\
\pm 8.9 \\
\end{array}$ & $>0.05$ & $\begin{array}{l}21.3 \\
\pm 9.6 \\
\end{array}$ & $\begin{array}{r}16.4 \\
\pm 7.7 \\
\end{array}$ & $.030^{*}$ \\
\hline $\mathrm{Alb}(\mathrm{g} / \mathrm{L})$ & $33.2 \pm 7.5$ & $30.9 \pm 5$ & $>0.05$ & $\begin{array}{l}31.3 \pm \\
3.8\end{array}$ & $\begin{array}{l}26.9 \\
\pm 5.3 \\
\end{array}$ & $0.03^{*}$ & $\begin{array}{l}31.2 \\
+5.6\end{array}$ & $\begin{array}{l}29.7 \pm \\
4.9\end{array}$ & $>0.05$ \\
\hline
\end{tabular}

Paired t-test.

P: statistical significant $<0.05 *$ and a highly significant. $<0.001 * *$

HB. serum hemoglobin, TRF \%, Transferrin saturation \%, ALT, Alanine tansaminase \& serum albumin.

Table (4) Epo, Iron and TRFS. \% for HCV+ve \& HCV-ve group

\begin{tabular}{|l|l|l|l|}
\hline Variable & HCV + ve group & HCV - ve group & P Value \\
\hline Total Epo dose $($ ug $/ 6$ m. $)$ & $718.3 \pm 58.3$ & $1937 \pm 400$ & $<0.001$ \\
\hline Total Iron dose $(\mathrm{gm} / 6 \mathrm{~m})$. & $1.117 \pm 0.23$ & $2.5 \pm 0.64$ & $<0.001$ \\
\hline TRFS. \% & $43.1 \pm 11.9$ & $29.7 \pm$ & $<0.001$ \\
\hline
\end{tabular}

P: statistical a highly significant. $<0.001$

P.>0.05(N.S).

Tab.(5) The Index Of Co Existing Diseases (ICED) In The Patients.

\begin{tabular}{|l|l|l|}
\hline ICED Score & $\mathrm{HCV}-\mathrm{ve}$ & $\mathrm{HCV}+\mathrm{ve}$ \\
\hline Asymptomatic & 19 & 9 \\
\hline 2 & 15 & 9 \\
\hline 3 & 6 & 5 \\
\hline Total & 40 & 23 \\
\hline
\end{tabular}

Tab.(6) Karnofsky Index(KI) Scoring In The Patients.

\begin{tabular}{|l|l|l|l|l|}
\hline KI score & $\frac{H C V+v e}{(23) \text { Males }}$ & Females & $\frac{H C V \text {-ve }}{\text { Males }}$ & Females \\
\hline$\leq 50$ & 6 & 5 & 3 & 10 \\
\hline$\geq 60$ & 8 & 4 & 13 & 14 \\
\hline Total & 14 & 9 & 16 & 24 \\
\hline P $>0.05$ N.S.
\end{tabular}

In HCV+ ve patients there was no statistically significant correlation between KI and blood HB, serum iron, TRFS\%, ALT and serum Albumin at 0,3 and 6 months of studied period $(\mathrm{P}>0.05)$.

Figure1 comparison of Transferrin saturation (TRFS) \% levels between the hepatitis c and control group.

\section{Mean TRFS\% for different months}

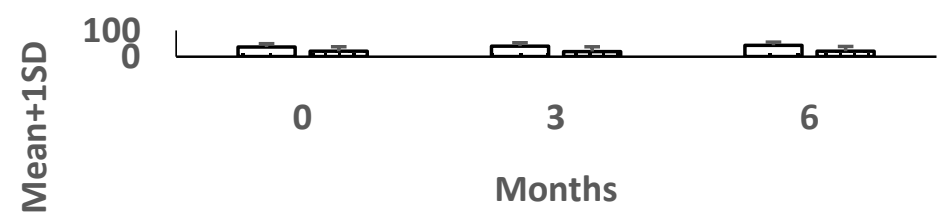

$\square \mathrm{HCV}+\triangle \mathrm{HCV}-$ 
Figure 2 comparison of IV monthly erythropoietin (Mircera) \& cumulative dose levels between the hepatitis $\mathrm{c}$ and control group .

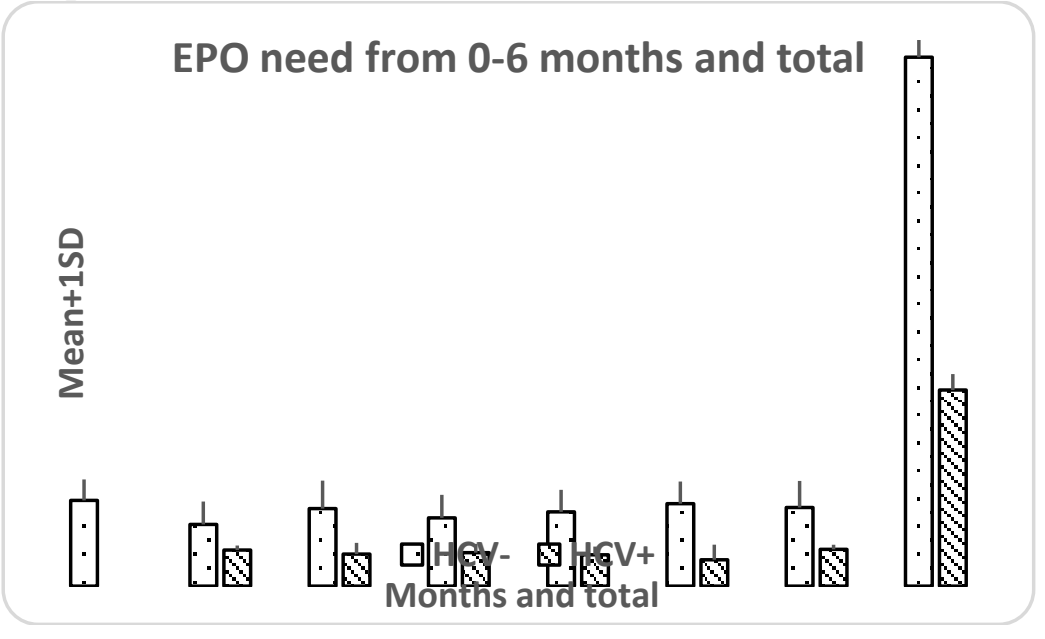

Figure 3 comparison of IV iron cumulative dose levels between the hepatitis c and control group.

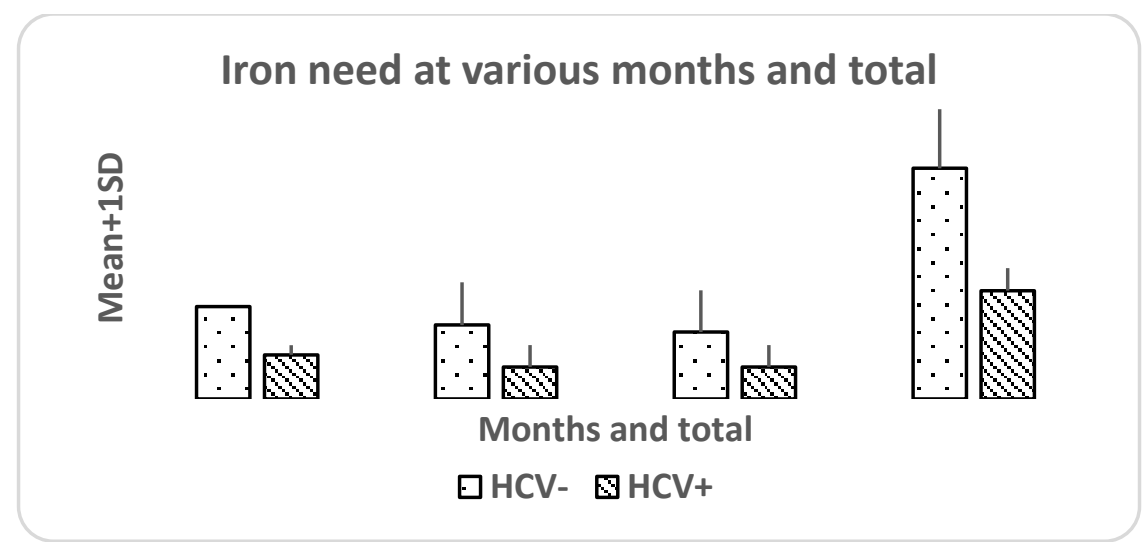

\section{Discussion}

ESRD Patients on regular dialysis support are usually anemic due to lack of EPO secretion from the kidney. A few exceptions include polycystic kidney disease where kidneys are able to maintain EPO secretion despite loss of other functions. In our study, HCV has emerged as another potential cause of EPO freedom in some dialysis patients as evidenced by study of 23 (hepatitis $\mathrm{C}$ positive group) patients who had less need for exogenous EPO and intravenous iron replacement throughout the study period compared with none in the matched control group of 40(hepatitis $\mathrm{C}$ negative group) patient. Also as a group, these patients required less EPO therapy in comparison with their age-matched, race-matched, and gender matched non-HCV patients on dialysis during the period of clinical stability with adequate dialysis
Red cell production in the body requires the presence of EPO and adequate iron stores. Erythropoietin is the major hormone required for red cell precursor proliferation in the bone marrow. It stimulates the blast forming units-erythroid in the bone marrow to mature into proerythro-blasts, which later form the circulating red cells. Its major site of production is the peritubular fibroblasts in the kidney. Some degree of endogenous EPO production also comes from the liver. ${ }^{(15)}$ This has been found to be significant especially in the fetus and in nephrectomized animals in previous studies. The exact site of EPO production in the liver is not clear. Some studies have pointed it out to be located in the Kupffer cells ${ }^{(16)}$ while others believe it to be within hepatocytes surrounding the central veins, along with contribution from the Ito cells in the space of Disse. (17) In either case, 
hepatonecrosis from inflammation from hepatitis or a regenerating liver post injury could potentially result in release of EPO from hepatocytes into the circulation.

The other major requirement for erythropoiesis is adequate iron stores. This is assessed mainly by calculating serum TRFS \% (serum iron/serum total iron binding capacity $x$ 100) and measuring circulating ferritin levels (because bone marrow biopsy to estimate iron stores is rarely performed). After dialysis therapy is initiated, almost all patients require periodic IV-iron supplementation to keep iron saturation in the range of $20 \%$ to $50 \%$ and ferritin levels between 100 and $800 \mathrm{ng} / \mathrm{mL}$ based on KDOQI guidelines. We obtained our data at least 6 months after dialysis begun to ensure clinical stability of these patients, to allow resolution of the deleterious effects of uremia on hematopoietic function, and to confirm achievement of adequate iron stores. Patients with $\mathrm{HCV}$ tend to have higher ferritin compared with non-HCV patients, as ferritin is an acute phase reactant that is released from the liver with hepatic inflammation. ${ }^{(18,19)}$ Although this may be the case in then on dialysis population, the infusion of IViron on dialysis elevates the ferritin levels, even in non-HCV patients. Exogenous iron replacement has been known to cause release of free iron and ox radical formation, which can damage cellular lipids and nucleic acids (20) and, thus, less iron requirement may be beneficial. Sahin et al. had found a lower requirement of IV-iron in dialysis patients with $\mathrm{HCV}^{(13)}$.

Alsaran et al ${ }^{(14)}$ found in their study that ESRD patients on $\mathrm{HD}$ with $\mathrm{HCV}$ infection have higher $\mathrm{Hb}$ and HCT levels compared with HCV-negative patients. Our study also showed the same results of high serum $\mathrm{Hb} \&$ iron levels in $\mathrm{HCV}$ +ve group in compared with non HCV group at $0,3,6$ months as shown it table (2).

The exogenous EPO requirement of patients with $\mathrm{HCV}$ was overall significantly lower. We hypothesize that the chronic inflamation as a result of HCV infection or the increased production from the regenerating liver cells causes increased circulating EPO - causing improved hematocrit in these patients. Quantifying the role of hepatic inflammation, however, is a difficult task as the commonly used markers like ALT are unreliable in dialysis patients.

Patients on dialysis in general tend to have lower ALT levels. ${ }^{(19,21)}$ Hepatitis C, unlike hepatitis B infection, has a greater tendency toward intermittent exacerbations and remissions, with a very variable and fluctuating ALT profile. Thus patients with $\mathrm{HCV}$ on dialysis may have normal ALT levels despite significant histological liver damage. ${ }^{(22)}$

It is estimated that $20 \%$ to $25 \%$ of $\mathrm{HCV}$ patients with normal ALT levels will have histological damage on liver biopsy. ${ }^{(23)}$

Because ALT elevation is not a reliable feature of dialysis patients with $\mathrm{HCV}$, it cannot be used as a surrogate marker to quantify inflammation in the liver. There have been reports of using the AST/ALT ratio as a predictor of hepatic inflammation both in the nondialysis and dialysis population with $\mathrm{HCV}$; however, this warrants further study $(24,25)$

Zumrutdal A etal ${ }^{(26)}$ also found a relationship between anemia, Liver disease, and hepcidin levels in hemodialysis patients with hepatitis. Probable lower serum hepcidin levels related with liver disease may have contributed to the improvement of anemia in hemodialysis patients. Since EPO hyporesponsiveness, EPO independence and the factors contributing to it have been investigated only in a limited number of studies. Interestingly, the common findings in those studies have consistently been an increased number of years on hemodialysis therapy and a correlation between hemoglobin and hemodialysis duration in EPOindependent hemodialysis patients. It is not immediately obvious which mechanisms contributed to the EPO independence in this subgroup of patients who have been on hemodialysis therapy for longer periods of time. So, the question "What stimulates erythropoiesis in these hemodialysis patients even in the absence of sufficient EPO production?" still needs to be 
answered for such patients with further studies both with and without hepatitis ${ }^{(26)}$.

Conclusion: we confirmed the need for lower EPO and IV iron requirement in our subset of patients with HCV Freedom from EPO or very low requirements usually prompts investigation for acquired renal cystic disease, renal cell carcinoma, or polycythemia Vera in dialysis patients. We suggest that it should be a reason to look for occult $\mathrm{HCV}$ infection, given the higher risk of acquiring this infection on hemodialysis and having normal ALT levels

\section{References}

1. Center for Disease Control. Recommendations for prevention and control of hepatitis $\mathrm{C}$ virus (HCV) infection and HCV-related chronic disease. MMWR Recomm Rep 1998; 47(RR-19):1-39.

2. Houghton M. Hepatitis $C$ virus. In: Fields B.N., Knipe D.M., Howley P.M. eds. Virology. Philadelphia: Lippincott-Raven Publishers, 1996.

3. Alter M.J. Prevention of spread of hepatitis C. Hepatology 2002; 36:S93-8.

4. Moraes C.R., Carrilho F.J., Bassit L.C., et al. Hepatitis $\mathrm{C}$ virus infection in hemodialysis patients from southern Brazil. Epidemiological data and genotypes. Hepatology 2000; 32:546 A.

5. Pujol F.H., Ponce J.G., Lema M.G., et al. High incidence of hepatitis $\mathrm{C}$ virus infection in hemodialysis patients in units with high prevalence. J Clin Microbiol 1996; 34:1633-6.

6. Sayiner A.A., Zeytinoglu A., Ozkahya M., et al. HCV infection in haemodialysis and CAPD patients. Nephrol Dial Transplant 1999; 14:256-7.

7. Tokars J.I., Miller E.R., Alter M.J., Arduino M.J. National surveillance of dialysis associated diseases in the United States, 1995. ASAIO J 1998; 44:98-107.

8. Vanderborght B.O., Rouzere C., Ginuino C.F., et al. High prevalence of hepatitis C infection among Brazilian hemodialysis patients in Rio de Janeiro: a one-year follow-up study. Rev Inst Med Trop Sao Paulo 1995; 37:75-9.

9. Sahin I, Arabaci F, Sahin HA, et al. Does hepatitis $\mathrm{C}$ virus infection increase hematocrit and hemoglobin levels in hemodialyzed patients? Clin Nephrol. 2003; 60:401-404.

10. Anand KHURANA, Allan E. NICKEL, Mohanram NARAYANAN, Charles J. FOULKS.effect of $\mathrm{HCV}$ infection on anemia in hemodialysis patients .Hemodialysis Int. 2008;12 : 94 -99.

11. MISKULINDC, ATHIENITESNV, YAN $\mathrm{G}$, et al: Co morbidity assessment using the Index of Coexistent Diseases in a multicenter clinical trial. Kidney Int 60:1498-1510, 2001

12. RETTIG R, SADLER J, MEYER K, et al: Assessing health and quality of life outcomes in dialysis: A report on an Institute of Medicineworkshop. Am J Kidney Dis 30:140-155, 1997

13. Sahin I, Arabaci F, Sahin HA, et al. Does hepatitis $\mathrm{C}$ virus infection increase hematocrit and hemoglobin levels in hemodialyzed patients? Clin Nephrol. 2003; 60:401-404.

14. Alsaran KA,Sabry AA,AlghareebAH,Al Sadoon G.Effect hepatitis c virus on hemoglobin and hematocrite levels in saudi hemodialysis patients . Renalfaliure Volume 31, Number 5, June 2009 , pp. 349354(6)

15. Simon P, Meyrier A, Tanquerel T, AngKS. Improvementof anemia in haemodialysed patients after viral or toxichepatic cytolysis. Br Med J. 1980; 280:892-894.

16. Gordon AS, Naughton BA. Mechanisms of extrarenalEPO (Ep) production. Exp Hematol. 1980; 8(Suppl 8):14-28.

17. Eckardt KU. Erythropoietin production in liver and kidneys.Curr Opin Nephrol Hypertens. 1996; 5:28-34. 
18. Shan Y, Lambrecht RW, Bonkovsky HL. Association of hepatitis $\mathrm{C}$ virus infection with serum iron status: Analysis of data from the third national health and nutrition examination survey. Clin Infect Dis. 2005; 40:834-841.

19. Caramelo C, Albalate M, Bermejillo T, et al. Relationshipbetween plasma ferritin and aminotransferase profile in haemodialysis patients with hepatitis C virus. Nephrol Dial Transplant. 1996; 11:1792-1796.

20. Nascimento MM, Suliman ME, Bruchfeld $A$, et al. Theinfluence of hepatitis $\mathrm{C}$ and iron replacement therapyon plasma pentosidine levels in haemodialysis patients.Nephrol Dial Transplant. 2004; 19:3112-3116.

21. Fabrizi F, Lunghi G, Finazzi $S$, et al. Decreased serum aminotransferase activity in patients with chronic renal failure: Impact on the detection of viral hepatitis. Am J Kidney Dis. 2001; 38:1009-1015.

22. Contreras AM, Ruiz I, Polanco-Cruz G, et al. End-stage renal disease and hepatitis $\mathrm{C}$ infection: Comparison of alanine aminotransferase levels and liver histology in patients with and without renal damage. Ann Hepatol.

23. Pradat P, Alberti A, Poynard T, et al. Predictive value of ALT levels for histologic findings in chronic hepatitis C: A European collaborative study. Hepatology. 2002;

24. Sheth SG, Flamm SL, Gordon FD, Chopra S. AST/ALT ratio predicts cirrhosis in patients with chronic hepatitis $\mathrm{C}$ virus infection. Am J Gastroenterol. 1998; 93:4448.
25. U” stu“ ndag Y, Bilezikc , i B, Boyacioglu S, Kayatas M, O"demir N. The utility of AST/ALT ratio as a non-invasive demonstration of the degree of liver fibrosis in chronic $\mathrm{HCV}$ patients on long-term haemodialysis. Nephrol DialTransplant. 2000; 15:1716-1717.

26. Azumrutdal and N.Sezgin Indian J Nephrol. 2012 Nov-Dec; 22(6): $\quad 415$ 418.doi: 10.4103/0971-4065.10603 